\title{
COVID -19 AND THE PARALYSATION OF WOMEN LIVELIHOODS IN MICRO- ENTERPRISES IN MASVINGO URBAN, ZIMBABWE
}

\author{
Sinikiwe Gwatidzo \\ Registrar's Department \\ Great Zimbabwe University, Box 1235 Masvingo, Zimbabwe \\ Bernard Chazovachii \\ Department of Rural and Urban Development \\ Great Zimbabwe University, Box 1235 Masvingo, Zimbabwe \\ E-mail: bchazovachii@gzu.ac.zw
}

\begin{abstract}
Covid-19 has fast become a global catastrophic pandemic affecting all facets of life, including people's livelihoods. Despite the devastating impact COVID-19 has caused across the globe, little has been researched on how lockdown intervention measures have affected livelihoods of entrepreneurial women. This study assesses how the conditions characterising the COVID-19 induced lockdown affected the livelihoods of Small and Medium Enterprises (SMEs) entrepreneurial women in the Masvingo Province of Zimbabwe. The study reveals that COVID19 lockdown in Zimbabwe was (and continues to be) marred with enforced restrictions on women in the informal sector. Women in the urban areas were the most affected. The vulnerability context among urban women was characterised by shock, stress and restlessness. Based on findings of this study, we advance that COVID-19 induced lockdown paralysed entrepreneurial women's capital assets thereby militating against their self-sustenance, selfreliance and advancement. The closure of markets, mobility permits, corruption on COVID-19 relief cash transfer and subsidised mealie-meal worsened the entrepreneurial women's shocks, stresses and restlessness. We therefore conclude that the impact of COVID-19 has not only compromised nations' food security and health systems, but most importantly paralysed entrepreneurial women's livelihoods, yet women in the African context, musha mukadzi without a mother there is no home.
\end{abstract}

Keywords: COVID-19, Entrepreneurial Women, Livelihoods, Mitigation.

\section{INTRODUCTION}

In the past, we have had global repeated epidemics such as smallpox in the $18^{\text {th }}$ and $19^{\text {th }}$ centuries, bubonic plague (1901-1907), 'Spanish' flu (1918-1919), polio (1944-1963) and ongoing HIV and AIDS (1982-to present). COVID-19 has fast become a global catastrophic pandemic affecting all spheres of life, including people's livelihoods. The pandemic has ruined health systems, interfered with human freedoms and disrupted the smooth-running of economies across nations of the world. Despite the devastating impact COVID-19 has caused across all spheres of life the world-over, little has been researched on how the World Health Organisation (WHO) - derived lockdown intervention measures have affected livelihoods of women, and especially entrepreneurial women. 
What is even more worrying is that in the $21^{\text {st }}$ century, epidemics at the global level have alarmingly increased with bubonic plague (1901-1907), 'Spanish' flu (1918-1919), polio (19441963), ongoing HIV and AIDS (1982-to present) and presently the COVID-19 (2019-to present). Droulet, Dominelli, Alston, Ersing, Mathbor and Wu (2015) confirm that globally, diverse kinds of adversities including epidemics, have amplified in power and scale in the recent years. Yet, although populations are generally affected by natural adversities of different magnitudes, inhabitants are not similarly affected as their levels of risk are different (Neumayer \& Plumper, 2007; Smyth \& Sweetman 2015). Smyth \& Sweetman (2015) observe that "while both females and males may be similarly susceptible to the deleterious magnitudes of catastrophes, females are mostly viewed as the most affected'. This means that to 'ignore women's capacities and focus only on men's abilities can adversely impact women, households and the whole community' (Drouet et al, 2015) at large. Individual women and those in groups who suffer marginalisation and discrimination are most vulnerable to the impacts of disasters. 'It is well-documented in the literature how the lifecycle intersects with the different structural vulnerabilities, which particular individuals face' (Sohrabizadeh, 2016). 'Every disaster is different and affects women and men differently according to the particular gender roles and relations within a specific community. Women have been estimated to be seven times more likely than men to die in disasters, and to receive less aid' (Bradshaw and Fordham, 2013). In many countries of the world, women are more likely to be numbered amongst the poorest, landless, and malnourished, and these existing vulnerabilities are worsened when a disaster strike. They are on the receiving end of any calamity even though they seem to be the most resilient and thrift. In fact, women are not only more affected by these problems, but also possess ideas and leadership to solve them. This is aptly captured by Ziwira (2020: 16) who notes thus:

However, as mothers, women have a way of appealing to the heart, the heart listens. Women are able to circumvent their vulnerability through deft navigation of spaces either in the rural locale or urban setting. Through their urgency, they can become their own masters and remodel intra-family relationships from an economic leverage that gives them a voice in decision making. Empowering women economically works in favour of the family unit because they are considered more thrift than men. African women have always had an affinity with the land which made it possible for them to provide for their families. As oracles they understood the spiritual connection between humanity and the land, which they celebrated through the change of seasons.

Worse still, women have the responsibility for the welfare of their households and family security in times of emergencies. In times of disaster, females are governed by cultural values systems which constraint mobility. This constrained mobility affects information accessibility for women to copy with the disaster, thus why more women succumb to death during disasters. This is corroborated by Alston (2015) who observes that following a disaster, young girls are particularly vulnerable to being withdrawn from education to assist with the workload, to forced child marriages, and human trafficking. Droulet, Dominelli, Alston, Ersing, Mathbor and Wu (2015) weigh in arguing that 'gender equality is a right and fulfilling this right is the best chance we have in meeting some of the most pressing challenges of our time from a health and economic sense. The gender discrimination, which is derailing the progress many women back, holds the world back too'. 'The 2030 agenda for sustainable development, embody a roadmap for sustainable progress that leave no one behind. Attaining gender equality and women 
empowerment is pivotal to each of the 17 SDG's, ensuring the rights of women across all goals while achieving justice and inclusive economies that work for all' (UN women, 2018).

In Zimbabwe, the closure of markets, mobility permits, corruption on COVID-19 relief cash transfer and subsidized mealie-meal left entrepreneurial women with even more shocks, economic stress and restlessness. It is against this backdrop that this study interrogates conditions characterizing COVID-19 induced lockdown, particularly how they affected the livelihoods of Small and Medium Enterprises (SMEs) of entrepreneurial women in Masvingo Province of Zimbabwe.

\section{WOMEN IN ZIMBABWE AND SMALL AND MEDIUM ENTERPRISES (SMEs)}

In any society, women are an integral part of the social and economic sectors. They play a leading role in the economic development and peace building of the nation. In Zimbabwe, one of the roles of the government is to formulate and develop legal and regulatory frameworks, promote and coordinate, monitor innovative financing schemes. In all these government activities, women play a leading role and should not be seen to be left behind or side-lined as has traditionally been the case, especially in colonial Rhodesia (see for example, Ziwira, 2020). The International Cooperative Alliance Report (ICA) (2015), reveals that Zimbabwe has over 4000 registered housing cooperatives and plus or minus half a million members countrywide, the majority of whom are women. Besides, there are 127 fishing cooperatives in the country which are sustaining families and contributing to the national food basket. As of December 2013, cooperatives at Siyaso in Mbare, Harare, largely dominated by women made estimated incomes of US dollar 32, 384 million from metal containers, welding and furniture, carpentry and welding, road side carpentry, uniform and work suits, plastic recycling for buckets and cups and school furniture. Government report by the Minister pointed out that there are 57 arts and craft cooperatives registered since 2009 spread across the country, which are involved in stone and wood carving, baskets and tie and dye. In 2001, 254 savings and credit cooperatives were registered. Between 2017 and 2019, the Small and Medium Enterprise Development Corporation (SMEDCO) which falls under the ambit of the Ministry, availed about 15 million dollars to boost the growth of small business. Most of the members in these registered cooperatives are women (GoZ, 2020). Unfortunately, women particularly in Zimbabwe still have difficulties in accessing formal banking products such as loans. As Ziwira (2020) reveals, so far, Zimbabwe has partnered with UN, Finance and Economic Development Ministry and RBZ to open the Zimbabwe Women's Micro Finance Bank but research is revealing that only $27 \%$ of women have access to formal banking products and accounting only for $10 \%$ of the total bank loans. A micro finance bank like ZWMB with the fairer sex at heart can go a long way in empowering women. This means that the potentials and opportunities for women especially those in Small and Medium Enterprises (SMEs) remain gridlocked such that realising their full potential will always be a challenge.

With regards to Small and Medium Enterprises (SMEs), there is generally no 'agreed' definition of an SME as it varies from one institution to another. The Government of Zimbabwe (GOZ) defines an SME as a business enterprise with 100 or less employees ((Mudzviti and Mawanza, 2014). Small Enterprise Development Corporation (SEDCO), defined an SME as an enterprise with 50 or less employees. The criterion used for defining an SME, include among other things the number of employees, net asset value, sales value and capital size. Ministry of Small and Medium Enterprise and Cooperative Development (MSMED) in Zimbabwe, classified SMEs in micro, small, and medium enterprises. For the purpose of this study, the term SME shall 
incorporate women in micro enterprises and the Ministry of Small, Medium Enterprises and Cooperative Development definition will be adopted (Mudzviti and Mawanza, 2014).

\section{ENTREPRENEURIAL WOMEN AND LIVELIHOODS}

A livelihood is the way people earn a living. It encompasses people's capabilities, assets and activities required to secure the necessities of life. It is regarded as sustainable when it can cope with, and recover from external shocks and stresses, and maintain its asset base. Successful livelihood strategies lead to a variety of economic and non-economic benefits, including greater income and more economically sustainable livelihoods; increased well-being better access to services such as health, water, power and education; reduced vulnerability to external trends, shocks and seasonality; improved nutrition and food security; and more sustainable use of natural resources. The chosen DFID's sustainable livelihoods framework in this study is very influential and widely used and adapted. The framework has vulnerability context which frames the environment in which poor people live. The environment in which women resides has a bearing on the hardships they face a direct impact on their assets and the livelihood options open to them. In this case the study refers to the women in an emergence situation. The context is associated with long-term trends and stresses which can be demographic, economic, political, environmental, shorter-term shocks or seasonal changes in prices, production, food availability, employment opportunities and health. These can be enduring sources of hardship, destroying people's livelihood assets or forcing them to dispose of assets as part of coping or survival strategies. In this regard, women are exposed to COVID-19 pandemic, which has caused stress and shocks among the micro entrepreneurs.

\section{Vulnerability Context}

The context is characterised by stress, shocks and incapacitation. The covid-19 pandemic has brought the national lockdown in both developed and developing nations and Zimbabwe is not an exception. The lockdown had been governed by the WHO (2020) regulations which quarantined the returnees and isolated the covid-19 infected and suspected patients, banned the non-essential services and activities and restricted mobility of people, goods and services. Most of the non-essential services were informal enterprises of which $61 \%$ of the African community and Zimbabwe in particular is not an exception. Most of the women were among the informal non-essential services whose livelihoods had been lockdown. Financial lockdown had resulted in food, shelter and clothing challenges hence shocks and stress characterised women business categorised as non-essential services. The lockdown had exposed the weak and the entrepreneurial poor among urban households. Although restrictions had limited the spread of the disease, interruption of market chains and trade of agricultural and non-agricultural produce, with significant potential impacts on the populations that depend on them for their livelihoods and their food and nutrition security characterised the lockdown. "Around 2 billion people$61 \%$ of the world' $\mathrm{s}$ working population - toil in the informal economy, and have little or nothing to protect them if they are unable to go to work' (ILO, 2017). 'They usually have neither sick pay nor health insurance and may not be eligible for government benefits given to furloughed (leave of absence) workers. The situation threatens to be particularly acute in Africa, where $86 \%$ of employment is informal' (ILO, 2017). 


\section{Assets, Capabilities, Capital}

These are the wide range of possessions which people in disaster possess or have access to and use to gain a livelihood. Livelihood assets are divided into various kinds of 'capital': human, social, natural, physical and financial. These are endowments and entitlements by women in disaster despite their vulnerability in affecting their potential to transform their lives. Livelihood assets have influence on women's institutional structures and processes. Assets can determine or lead to existence of institutions and laws for sustainable resource utilisation. Assets can establish organisations that generates rules and regulations for employment creation and other livelihood strategies. Likewise, institutions can affect access to assets and influence capabilities.

\section{Livelihood Strategies}

These are strategies deployed by people or households in shock and stress to regain a sustainable way of life. Households would be making use of assets at their disposal to earn a living. Access to assets could be influenced by one's capacity and capability in times of emergencies. Capacity could be influenced by structures and processes which could be laws, rules by government or private entities, cultural values systems of the society in disaster. In Figure 1, transforming structures and processes has influence on access to capital assets. In the context of COVID-19, lockdown regulations had banned, restricted mobility and access to assets and the capability of women in informal and non -essential services (GoZ, 2020). So, transforming structures had influence on the demise of informal non-essential services. Due to lockdown measures, copying with shocks would depends on the capacity and capability of individual, community and institution. The level of affection would be determined by the capacity of individual to copy with the stress. The highly affected households without supporting institutions such as social insurance systems would go the vulnerability pathway while those with collateral security and access to credit facilities would find themselves in the resilience pathway. Livelihoods thinking has also contributed to our understanding of resilience. Reaction to the disturbances by the disaster has either a resilience or a vulnerability pathway. In the context of the COVID -19 pandemic, the pathway followed by entrepreneurial women in business determine whether their livelihoods are demised or remained mythical. 


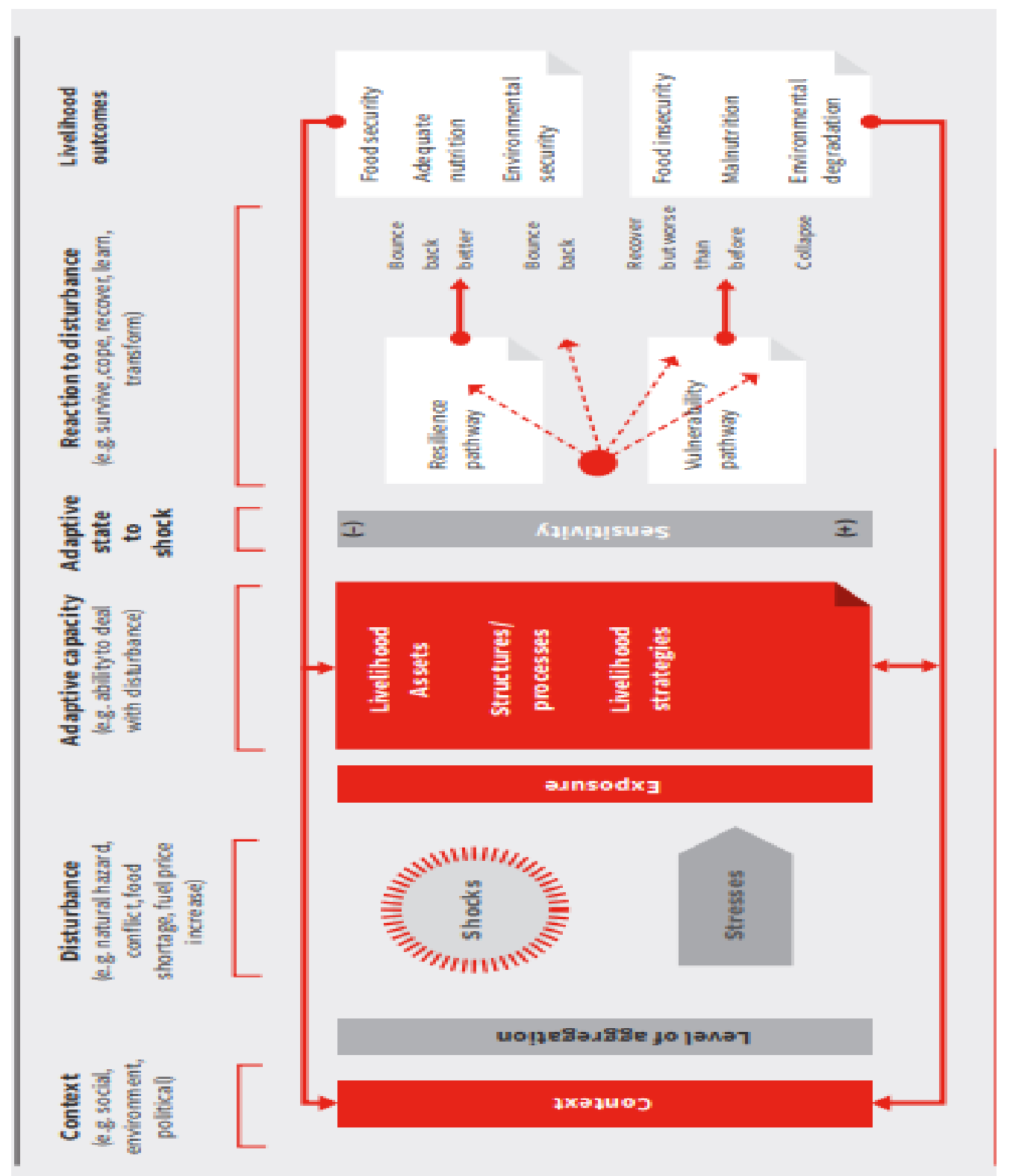

Figure 1. Sustainable Livelihoods Approach (Aid, 2012).

\section{MATERIALS AND METHODS}

\section{Research Design}

A case study was used to enable the research to "explore an issue or a setback case as a specific illustration" as advised by Creswell \& Creswell (2013: 57). The use of a case study was considered ideal because of its capacity to address the 'how' and 'why' questions of the contemporary problems (Gonye, 2016). The research design allowed the researchers to assess how the conditions characterising COVID 19 induced lockdown affected the livelihoods of women in entrepreneurship. Using a single district ensured an in-depth analysis to the phenomenon under study. 


\section{Sample}

Masvingo City Council Register for The Vendors, Masvingo Informal Trader's Association, Masvingo Cross borders association were used to locate respondents for the study. Respondents were purposively sampled, and snowball was used to identify respondents during the COVID-19 induced lockdown.

\section{Instrumentation}

Interviews and focus group discussions and document analysis were used in gathering data. Key informant interviews were done with the informal traders' representative, cross borders association representative and the Ministry of Small and Medium Enterprises representative. The focus of the interviews with vendors was on how they were affected by the lockdown. A focus group discussion (FGD) was held with the ministry representative, vendor representative and the two associations' representatives. Focused group discussions were held with aforementioned key informants to ensure trustworthiness and credibility of the findings as the researchers compared the responses. Interviews were chosen for the small sample of key informants and vendors and the two association representatives. The interviews allowed respondents to comment on women vulnerability, assets, and capabilities All key participants, vendors and the two associations targeted through these tools comprised participants who had 'stories to tell' (Creswell \& Creswell, 2013:155) and who could "purposefully inform an understanding" (Gonye, 2016:60) on the level of affection the lockdown has had on women livelihoods. Data were thematically analyzed to assess how the conditions characterising the COVID 19 induced lockdown affected the livelihoods of entrepreneurial women. Participants were informed that the study was of a worthwhile scholarly purpose. They were assured of the freedom to withdraw even after signing the consent forms. It was due to the code of ethics that this was done, as a requirement to avoid infringing the rights of participants and for the avoidance of harm to participants.

\section{PARALYSATION OF ENTREPRENEURIAL WOMEN'S LIVELIHOODS BY COVID- 19 INDUCED LOCKDOWN}

The enforced 21-day and 14-day government induced lockdown characterised by quarantine, bans and restrictions on the movement of goods and people had significant socio-economic, repercussion on women livelihoods (Chingarande, 2020:1). This implied that the lockdown had stopped the vending business as police enforced the lockdown provisions. The lockdown has put to an end the informal transport business (mushikashika). The lockdown has worsened the inflationary environment for women in business as their finances were also locked down. All this stressed the micro business community especially women enterprises. The above sentiments are demonstrated by the following verbal quotes:

It is now 21 plus 14 days with my vehicle parked. My drivers have decided to go to their rural areas as they have no money for rentals. This has brought my business to an end. There is no hope for private transport business again in Zimbabwe (Cross border representatives) 


\section{COVID-19 INDUCED LOCKDOWN AND LIVELIHOOD ASSETS}

\section{Human Capital}

COVID-19 induced lockdown has paralysed women who had the capacity to self-sustain themselves in business. Focus group discussions revealed that lockdown had put to an end to physical interaction in business due to the 'stay at home' mantra. The physical interaction used to allow women to use one single smart phone for their transaction. The stay at home mantra disrupted the low-cost approach to 'Eco cash transactions by women in business. Women at Chitima market in Masvingo had no WhatsApp and email infrastructure within their business networks. Some had no skills to perform WhatsApp and use emails in business transactions. The lockdown had a death blow to women capabilities. Women living with disabilities engaged in vegetables business had no capacity to practice mobile marketing recommended by the level 2 lockdown regulations. This implied that informal business was for women with open trucks facilitating mobility. Most of the Chitima market entrepreneurs had no personal truck for mobile marketing, hence grounding their enterprises. Use of online eco cash transactions by women in business made them to suffer transaction costs which carried up to $2 \%$ in charges.

\section{Physical Capital}

Interviews confirmed that dreams of women in Masvingo were shattered as 35 tonnes of tomatoes and 21 tonnes of avocados rotten in the Fruit and Vegetables Market that was shut down during the lockdown. One key informant revealed that;

'There are 35 tonnes of bananas, 21 tonnes of avocadoes and an unspecified quantity of tomatoes that have either been thrown away or are rotting because of the closure of the market'.

The above sentiments are demonstrated by the following verbal quotes:

These products were already ordered when the Masvingo District Covid-19 Taskforce ordered the closure of the market. Seven trucks of bananas and four trucks of avocados were already on the way when we got the order to shut down (Vendor 1).

Farmers threw away their tomatoes while bananas and avocados started rotting at Chitima and Tanaiwa market at the rank, where they were stashed away with few hours of trading time per day. This caused congestion and created serious inefficiencies. Vendors further incurred huge loss due to market decentralisation on the recommendation of the COVID 19 task force, who recommended that farmers deliver produce to all suburbs of Masvingo at designated places i.e. in Rujeko, Mucheke, Majange, Rhodene, West and Victoria Ranch (Informal traders association representative).

However, lack of transport to engage in mobile marketing of perishable goods resulted in rotten produce and collapsed of the business. Women entrepreneurs who had no communication gadgets such as smartphones could not engage in online procurement. The closure of the market jeopardised fruits and vegetable farmers' prospects. Closure of roads to Chitima also shut down all opportunities for women in fruit and vegetable marketing in Masvingo. Chitima was the main informal market where women could get produce for resale. 


\section{Financial Capital}

Key informant interviews revealed that the three days' notice period before the lockdown left farmers with no option but to sale their perishable at give-away process. Financial saving for the entreprenuers suffered as farmers started to rely on mega proceeds. It was risk for Small Enterprse Development Cooperative to give credit facility to women micro scale entrepreneurs, who were operating below capacity due to lockdown regulation. The shrinking financial capitals had significant implications for emergence resilience. In contemporary society, of all the capitals, financial capital is the most easily convertable to other forms of capital as in postdisaster, investment of financial capital would result in reconstruction of physical assets and other support services necessary. The social welfare fund to cushion women in entrepreneurship for three months was a far cry from reality as it could not address the entire array of needs by the vulnerable women.

\section{Natural Capital}

Document analysis confirmed that fruits and vegetables had transformed urban livelihoods especially for unemployed women in Masvingo. Presence of perennial rivers, streams and a lake in and around Masvingo has made Chitima and Tanaiwa market lucrative sources of livelihood. With high unemployment levels evidenced in Masvingo, the closure of private commuters disturbed easy supply of fruit and fresh vegetables to the market. In a focus group discussion, the closure of the market made farms and plots inaccessible to middleman. In the context of a COVID-19, natural capital represents basic necessities that support human life. Delinking farms, plots and rivers and dams made fruits and vegetable dealers miserable. Fishery business collapsed as fresh fish could not reach the market in time. The lockdown compelled those who alternatively engaged illegal peri-urban small-scale mining to return to their original rural home. Most of them ended up selling their assets to raise bus fares.

\section{Social Capital}

Revelations from a focus group discussion confirmed that closure of markets and movement restrictions disturbed business networks, trust and mutual understanding that bind the entrepreneurial members together. Trust was compromised by the absence of physical contact. Bonding as a form social capital was affected as the networks of women with similar demographic, social or ethics status as well as any among communities, individuals who already knew each other could not be realised due to the uncertainty and information asymmetry characterised by COVID-19 induced lockdown. Bridging social capital was ultimately disrupted as the dissimilarities in age, socio-economic condition, ethnicity, brought mistrust, uncertainty, risks as COVID-19 restrictions worsened uncertainty and risks. Reports of more deaths in developed nations heightened threats thereby adversely affecting recovery of women enterprises in Masvingo. So, the decease of capital assets threatened the vulnerability context of women enterprises.

\section{COVID-19 INDUCED LOCKDOWN AND CAPABILITIES}

Access to assets is critical for sustainable livelihoods. Women in business especially those in the medium enterprises, were affected by the suspension of airlines as they could not access international markets such as China and Turkey, where they used to procure some wares for resale. Lockdown and quarantine measures meant they would spend up to thirty-five days in between destinations. Furthermore, the ban on movement of private transport for small 
businesses meant that they could not possibly move anywhere. Mobility restrictions resulted in a financial lockdown. The informal fruits and vegetable traders and inter-city mobility of informal traders were affected due to constrained mobility. The pandemic led to the closure of source and outlets markets thereby compromising relationship, reciprocity, integration and social networks of women in business. Access to shared knowledge and skills with colleagues on business norms and values was limited. Limited exchange of goods disturbed the financial flows especially the informal money market business. Permits for business transactions amongst butcheries led to beef market lockdown. Limited government transport and travel permits restricted women access to potential market for fruits and vegetable dealers, informal money market dealers and the sale of second hand clothes. Restricted social capital constrained operations of women in market gardening and second hand clothing dealers. Goods and services were in accessible to both small and medium enterprises. The ban of the physical capital (market centre) affected entrepreneurial women's capacity to access social, financial, human, natural and physical resources for business.

Key informants revealed that transforming structures and processes entails government pronouncement on the extension on the lockdown and the enforcement of laws using existing institutions like the police which affects access to assets and influence their sustainable utilisation. Cultural norms impede entrepreneurial women's access to cross border trading in times of emergencies. Short cults done by men through illegal and informal routes to South Africa barred married women to follow that resilient pathway. Only single and unmarried women could engage in such survival strategies. More women particularly the married ones seductively succumb to the vulnerability pathway which led to the demise of their livelihood's alternatives. Livelihood strategies are influenced by sustainable utilisation of assets in line with the policies, laws and institutions of the state. The restrictions, through the stay at home mantra led more to vulnerability than resilience pathway. The closure of markets, permits for mobility, corruption on the distribution of COVID-19 relief cash transfer and subsidised mealie-meal worsened the shocks and stresses and collapse of entrepreneurship spirit among women in business.

\section{CONCLUSION AND RECOMMENDATIONS}

The conditions characterising COVID-19 prevention and mitigation was marred with enforced government 21 day and 14-day induced lockdown characterised by quarantine, bans and restrictions on the movement of goods and people. The vulnerability context of the entrepreneurial women is characterised by shocks, stress and incapacitation. COVID-19 induced lockdown paralysed women's physical, social, natural, human and financial capital thereby militating their self-sustenance in business. The closure of markets, permits for mobility, worsened the shocks and stresses associated with entrepreneurial women. The capacity and capability of entrepreneurial women were compromised by cultural traditions and restrictions. The stay at home mantra, closure of market led to the collapse of entrepreneurship spirit among women in business. This has led to persistent food insecurity, malnutrition and restlessness. We therefore conclude that the impact of COVID-19 has not only compromised nations' food security and health systems, but most importantly paralysed entrepreneurial women's livelihoods, yet women in the African context, musha mukadzi - without a mother there is no home. Local women support institutions acting as insurances must be established to carter for entrepreneurial women in business for a resilience pathway to be realised. 


\section{REFERENCES}

Alston, M. (2015). Women and Climate Change in Bangladesh, London and New York: Routledge.

Aid, C. (2012). Thriving, resilient livelihoods: Christian Aid's approach. Briefing, October.

Bradshaw, S., \& Fordham, M. (2013). Women and girls in disasters.

Chingarande, D. (2020). Treasury yet to release COVID-19 funds, News Day, 13 April, 1-24.

Creswell, J.W \& Creswell, W. (2013). Qualitative inquiry and research design: choosing among five among five approaches. London, Sage publishers.

Droulet, J., Lena D., Alston, M., Ersing, R., Mathbor, G., \& Wu,H. (2015). Women rebuilding lives post-disaster: innovative community practices for building resilience and promoting sustainable development, Gender \& Development, 23(3), 433-448.

Gonye, J. (2016). Forms and motivations of plagiarism by first-year students at a university in Zimbabwe: implications for teaching communication skills. Dzimbahwe Journal of Multidisciplinary Research, 1(2), 56- 72.

GoZ. (2020). COVID-19; what you need to know: The Standard 12-18 April 20.

IL. (2017). World Social Protection Report 2017-19: Universal social protection to achieve the Sustainable Development Goals International Labour Office - Geneva: ILO.

ICA Report. (2015). Ministerial statement on the state of co-operatives in Zimbabwe, VERITAS website.

Mudzviti, G., \& Mawanza, W. (2014). An Analysis of the Root Causes of Small and Medium Sized Enterprises (SMEs) Failure in Zimbabwe During the Period, Beitbridge, Zimbabwe. Zimbabwe international journal.org, 3(5).

Neumayer, E., \& Plümper, T. (2007). The gendered nature of natural disasters: the impact of catastrophic events on the gender gap in life expectancy, 1981-2002. Annals of the Association of American Geographers, 97(3), 551-566.

Smyth, I., \& Sweetman, C. (2015). Introduction: Gender and Resilience, Gender \& Development, 23(3), 405-414.

Sohrabizadeh, S. (2016). The Neglect of Women's Capacities in Disaster Management Systems in Iran: A Qualitative Study. Indian Journal of Gender Studies, 23(3) 467-480.

UN Women. (2016). Time to act on gender, climate change and disaster risk reduction. The United Nations Entity for Gender Equality and the Empowerment of Women.

WHO. (2020). Timeline of WHO's response to the pandemic from 31 December 2019, WHO Press Conference, 17(2), 18-30.

Ziwira, E. (2020). Empowering women, small businesses through gender equality, Herald 15 April 2020, Harare, 16.

\section{Copyrights}

Copyright for this article is retained by the author(s), with first publication rights granted to the journal. This is an open-access article distributed under the terms and conditions of the Creative Commons Attribution license (http://creativecommons.org/licenses/by/4.0/) 